\title{
The Influence of Unsteadiness on the Analysis of Pressure Gain Combustion Devices
}

Daniel E. Paxson

Glenn Research Center, Cleveland, Ohio

Tom Kaemming

Innovative Scientific Solutions Inc., Dayton, Ohio 


\section{NASA STI Program . . . in Profile}

Since its founding, NASA has been dedicated to the advancement of aeronautics and space science. The NASA Scientific and Technical Information (STI) program plays a key part in helping NASA maintain this important role.

The NASA STI Program operates under the auspices of the Agency Chief Information Officer. It collects, organizes, provides for archiving, and disseminates NASA's STI. The NASA STI program provides access to the NASA Aeronautics and Space Database and its public interface, the NASA Technical Reports Server, thus providing one of the largest collections of aeronautical and space science STI in the world. Results are published in both non-NASA channels and by NASA in the NASA STI Report Series, which includes the following report types:

- TECHNICAL PUBLICATION. Reports of completed research or a major significant phase of research that present the results of NASA programs and include extensive data or theoretical analysis. Includes compilations of significant scientific and technical data and information deemed to be of continuing reference value. NASA counterpart of peer-reviewed formal professional papers but has less stringent limitations on manuscript length and extent of graphic presentations.

- TECHNICAL MEMORANDUM. Scientific and technical findings that are preliminary or of specialized interest, e.g., quick release reports, working papers, and bibliographies that contain minimal annotation. Does not contain extensive analysis.

- CONTRACTOR REPORT. Scientific and technical findings by NASA-sponsored contractors and grantees.
- CONFERENCE PUBLICATION. Collected papers from scientific and technical conferences, symposia, seminars, or other meetings sponsored or cosponsored by NASA.

- SPECIAL PUBLICATION. Scientific, technical, or historical information from NASA programs, projects, and missions, often concerned with subjects having substantial public interest.

- TECHNICAL TRANSLATION. Englishlanguage translations of foreign scientific and technical material pertinent to NASA's mission.

Specialized services also include creating custom thesauri, building customized databases, organizing and publishing research results.

For more information about the NASA STI program, see the following:

- Access the NASA STI program home page at http://www.sti.nasa.gov

- E-mail your question to help@sti.nasa.gov

- Fax your question to the NASA STI Information Desk at 443-757-5803

- Phone the NASA STI Information Desk at 443-757-5802

- Write to: STI Information Desk NASA Center for AeroSpace Information 7115 Standard Drive Hanover, MD 21076-1320 


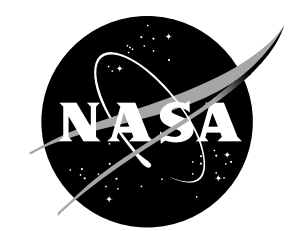

\section{The Influence of Unsteadiness on the Analysis of Pressure Gain Combustion Devices}

Daniel E. Paxson

Glenn Research Center, Cleveland, Ohio

Tom Kaemming

Innovative Scientific Solutions Inc., Dayton, Ohio

Prepared for the

51st Aerospace Science Conference

sponsored by the American Institute of Aeronautics and Astronautics

Grapevine, Texas, January 7-10, 2013

National Aeronautics and

Space Administration

Glenn Research Center

Cleveland, Ohio 44135 
This report is a formal draft or working paper, intended to solicit comments and ideas from a technical peer group.

This report contains preliminary findings, subject to revision as analysis proceeds.

Level of Review: This material has been technically reviewed by technical management.

Available from

NASA Center for Aerospace Information 7115 Standard Drive

Hanover, MD 21076-1320
National Technical Information Service 5301 Shawnee Road Alexandria, VA 22312

Available electronically at http://www.sti.nasa.gov 


\title{
The Influence of Unsteadiness on the Analysis of Pressure Gain Combustion Devices
}

\author{
Daniel E. Paxson \\ National Aeronautics and Space Administration \\ Glenn Research Center \\ Cleveland, Ohio 44135 \\ Tom Kaemming \\ Innovative Scientific Solutions Inc. \\ Dayton, Ohio 45440
}

\begin{abstract}
Pressure gain combustion (PGC) has been the object of scientific study for over a century due to its promise of improved thermodynamic efficiency. In many recent application concepts PGC is utilized as a component in an otherwise continuous, normally steady flow system, such as a gas turbine or ram jet engine. However, PGC is inherently unsteady. Failure to account for the effects of this periodic unsteadiness can lead to misunderstanding and errors in performance calculations. This paper seeks to provide some clarity by presenting a consistent method of thermodynamic cycle analysis for a device utilizing PGC technology. The incorporation of the unsteady PGC process into the conservation equations for a continuous flow device is presented. Most importantly, the appropriate method for computing the conservation of momentum is presented. It will be shown that proper, consistent analysis of cyclic conservation principles produces representative performance predictions.
\end{abstract}

\section{Introduction}

Pressure gain combustion (PGC) refers to a process whereby there is a rise in the averaged total pressure across the device in which the combustion is taking place. Typically, the device has fixed volume (i.e., no pistons). The pressure rise is in contrast to the more typical pressure loss associated with conventional, steady combustion utilized in aircraft propulsion and electric power generation systems. The pressure rise can be used with a nozzle to produce increased thrust in a ram propulsion application, or to provide increased availability to the downstream turbine in a gas turbine application. This enhanced performance potential of PGC over conventional combustion has been the impetus for many experimental and analytical investigations in the aerospace community over at least the past decade (Refs. 1 to 16).

Pressure gain combustion may be achieved with detonative or deflagrative chemical reactions. In either case however, the complete PGC process is periodic (i.e., pulsed), and therefore fundamentally unsteady. Referring to Figure 1, the working fluid within a given chamber undergoes a cyclic process that roughly consists of three phases: 1) chamber filling; 2) rapid, confined combustion or chemical heat release; 3) chamber exhaust or blowdown. The combustion chambers, of which many are usually envisioned to comprise a full combustor unit, may be fixed or rotating. The combustion chambers are typically valved at one or both ends. Valves may be of the aero (i.e., fluidic) or mechanical variety.

In a propulsion or power system, PGC devices may be coupled to continuous flow, normally steady components such as a turbines and nozzles. When analyzing the potential performance of such systems, particularly at the fundamental (i.e., preliminary) level, this coupling of seemingly disparate operational modes can lead to confusion. However, careful observance, integration and application of traditional control volume and control mass thermodynamic cycle equations can provide representative performance estimates. This paper outlines a methodology for doing so. A relatively simple mathematical model for the PGC device is presented. The appropriate integrals for assessing periodic mass, momentum, and energy flux are derived, and the implications and interpretations of their forms are discussed. 


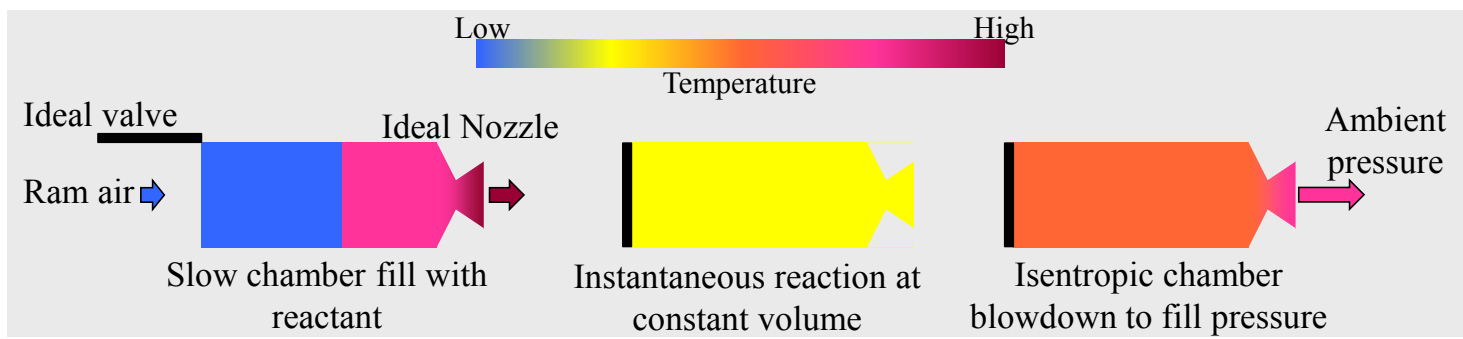

Figure 1.-Schematic of a basic, thrust producing PGC with cycle stages. Colors represent qualitative temperature.

\section{Notional PGC Process}

In order to estimate limits of performance, and to understand the fundamental operation of PGC devices, it is often useful to develop low order models(Refs. 2 to 4, 6, and 16). However, if such models are to be meaningful, they must account for the impact of fundamental unsteadiness. This will be illustrated using the basic, thrust-producing PGC engine concept, as illustrated schematically in Figure 1. This engine is represented by the Atkinson cycle. In many recent publications, this has also been referred to as the Humphrey cycle. As illustrated in the T-s diagram of Figure 2, the idealized version of this cycle is described by the following phases: a) isentropic (ram) compression (stations 0 to 3 ), b) constant volume heat addition (stations 3 to 4), c) isentropic expansion in the combustion chamber and nozzle (stations 4 to 9), and d) isobaric heat rejection (stations 9 to 0 ). It is assumed that the ram compression is steady and provides high pressure air for a multitude of combustion chambers. Each chamber is assumed to contain a converging/diverging exhaust nozzle which serves to limit the chamber Mach number (including the refill period) to a negligibly small value, and to expand (accelerate) the post-combustion fluid to ambient pressure. Each chamber also contains an ideal inlet valve which opens to allow refilling and closes to allow combustion and blowdown. In order to simplify the subsequent analysis, the classical air standard cycle analysis assumptions are also used: the fluid properties in each vessel are spatially uniform; the working fluid is a thermally and calorically perfect gas; the mass of the fuel is negligible. Finally, in order to remove the complexity of the notional PGC device (i.e., the need for an ideal exhaust valve), the chemical combustion reaction is assumed instantaneous.

Along with the Atkinson cycle, Figure 2 also shows the well-known idealized ram Brayton cycle for the same specific heat addition parameter and flight Mach number. The heat addition parameter is defined as follows.

$$
q_{0}=\frac{\Delta h_{v}(f / a)}{c_{p} \hat{T}_{0}}
$$

Figure 2 is helpful in that all of the fluid states comprising each cycle can be visualized, and the reduced entropy associated with constant volume combustion (compared to constant pressure combustion) is clear. However, for the case of unsteady PGC integrated into a ram propulsive device, the figure can be misleading for several reasons.

The first reason involves the types of thermodynamic cycle analyses used to predict cycle performance (i.e., control mass or control volume), and their traditional associations with Brayton and Atkinson cycles. By presenting only the thermodynamic states and paths in Figure 2, it is not possible to identify where work is done by or on the working fluid. For example, in a control mass analysis (i.e., a fixed mass with changing volume, such as a piston/cylinder) work is done by the fluid during both expansion and constant pressure heat addition phases. Similarly, work is done on the fluid during compression and constant pressure heat rejection phases. In a control volume analysis (i.e., a fixed volume with surfaces across which fluid flows) work is done by the fluid only during the expansion phase, and is done on the fluid only during the compression phase. 


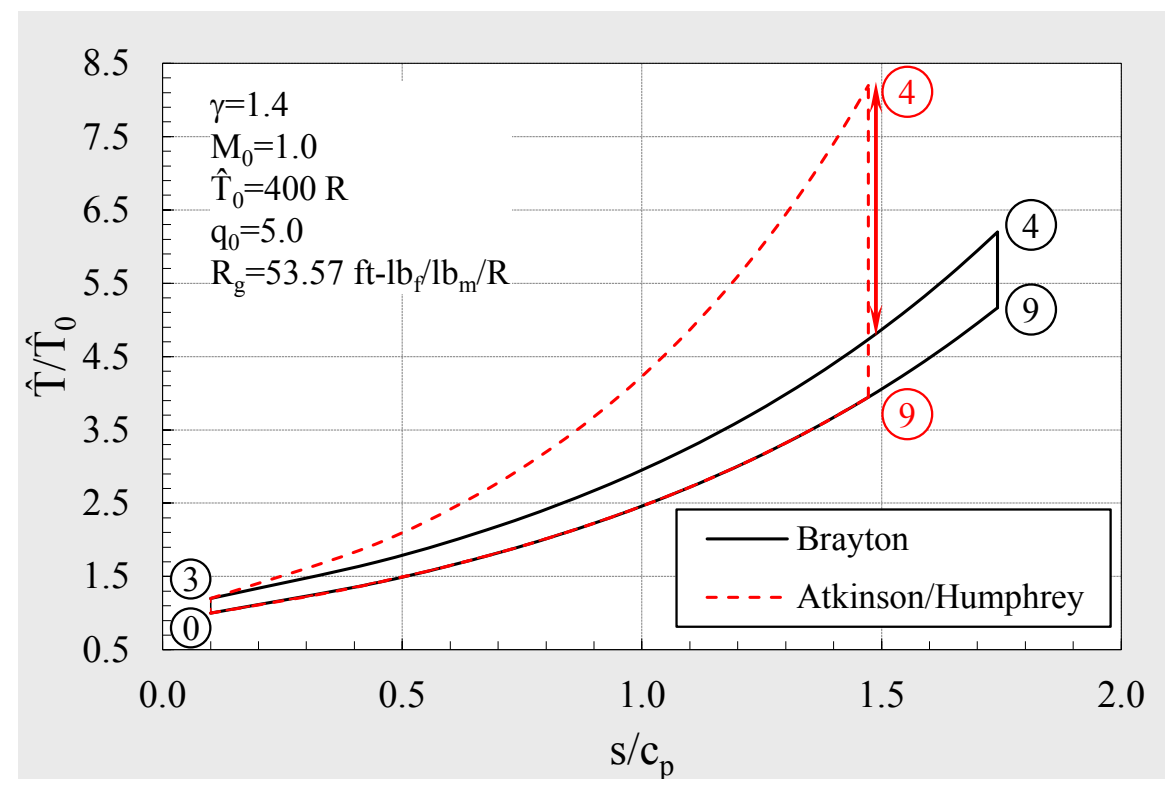

Figure 2.-T-s diagram of control volume Atkinson and Brayton cycles with the same ram compression and specific heat addition.

The Brayton cycle is nearly always analyzed using a steady, control volume analysis because the gas turbine and ramjet components are, in fact, steady flow, control volumes. The classical Atkinson cycle diagram is typically analyzed with a control mass analysis, since it was (and is still) primarily implemented in piston-based engines. If these respective analyses are used in interpreting the Brayton and Atkinson cycles shown in Figure 2, there is no convenient way to visually compare the net work, and therefore thermodynamic efficiency obtained from each.

In this paper, the Atkinson cycle shown in Figure 2 is performed by a PGC device with continuous flow components fore and aft. Heretofore referred to as the PGC Atkinson cycle, it requires a control volume form of analysis, and can therefore be compared in many ways directly with the Brayton cycle. However, there is a critical distinction, which leads to the second somewhat misleading aspect of Figure 2, namely, the interpretation of the states shown.

In the context of the ram device considered here, all the Brayton cycle states are fixed in time and space, as previously explained. Thus, each point on the Brayton cycle can be directly related to a specific physical location in the engine, and the properties at that point do not change. In a classical piston-based Atkinson cycle each point on the T-s diagram can be related to a different moment in time; however, the mass is fixed. Therefore, since network and other performance parameters calculable from a T-s diagram are on a per-unit-mass (i.e., specific) basis, time variation becomes irrelevant. All that is needed to complete a classical Atkinson cycle analysis are the heat added, and the system volume change during compression and expansion. For the PGC Atkinson cycle, the static states at stations 0, 3, and 9 are fixed in time, as in the Brayton cycle. However, the state at station 4 in the PGC Atkinson cycle combustion chamber varies with time through the range of values shown by the vertical red arrow in Figure 2 . This occurs over the course of the blowdown and refill stages as fluid crosses the fixed volume boundaries. It results in non-uniformity in the exhaust flow which is the primary manifestation of fundamental unsteadiness. This combination of steady and unsteady phases of the cycle makes the PGC Atkinson cycle analysis approach different from both classical Atkinson and Brayton cycle analyses. Assessing the impact of this unsteadiness is the main subject of this paper. 


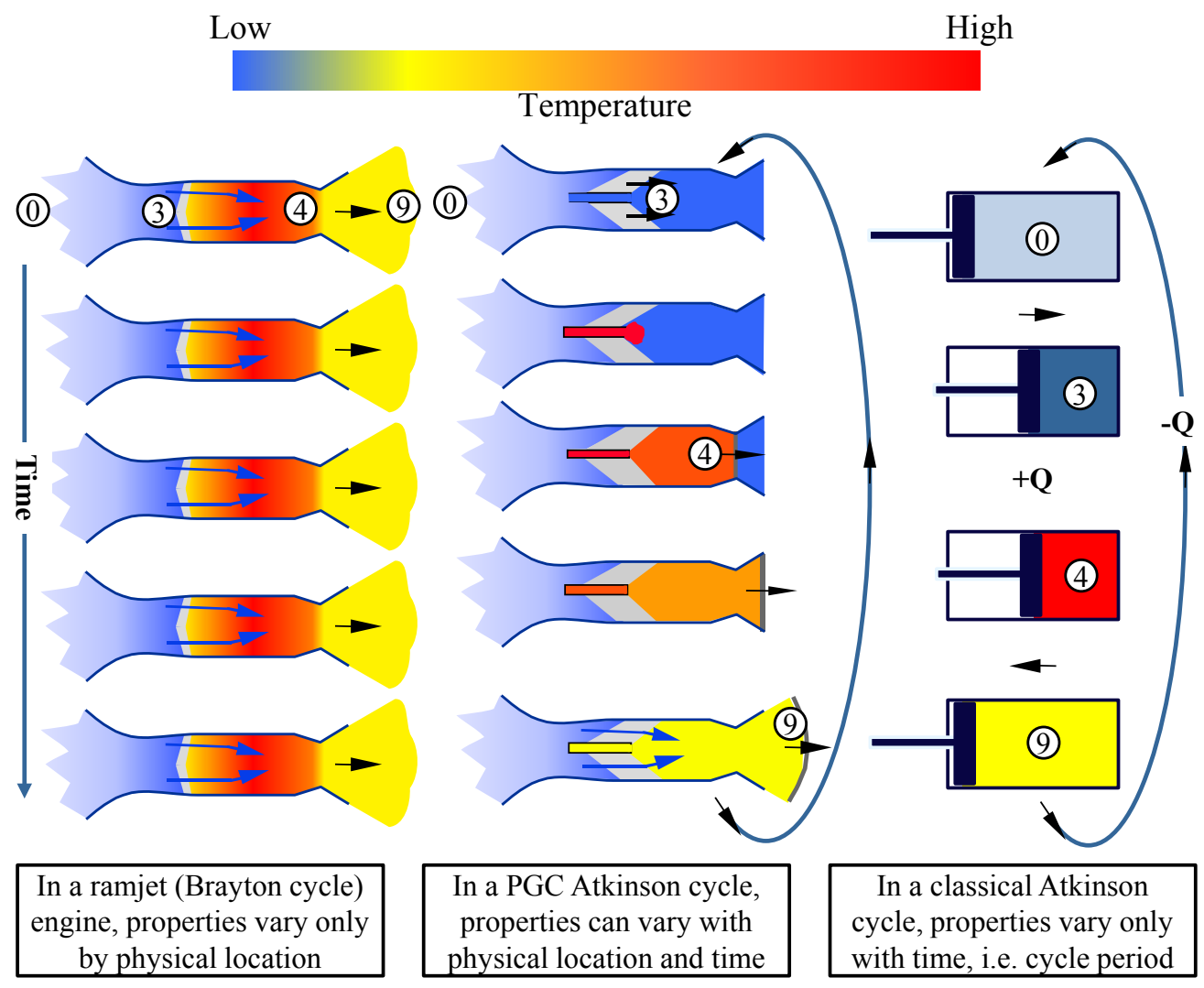

Figure 3.--lllustration showing the dependence of the PGC Atkinson cycle states on both time and physical location. Colors represent qualitative temperature.

For reference and clarity, a graphical rendering of the issues just discussed is shown in Figure 3. For the Brayton cycle, in this illustration a ramjet, the thermodynamic properties are a function only of physical location. In contrast, for the classical Atkinson cycle, the thermodynamic properties are a function only of time, or cycle period. The PGC Atkinson cycle is essentially a hybrid of these two cycles, in that the inlet properties are a function only of physical location, while the combustor and nozzle properties are a function of both physical location and time due to its unsteadiness.

The remainder of this paper will provide an appropriate means of analyzing the unsteady PGC Atkinson/Humphrey cycle, and some potential consequences of inappropriate analyses. Mass and energy conservation equations will be developed first. From these it will be shown that the mass-averaged temperature at station 4 has significance in that it represents the total specific enthalpy available for expansion. Next, the specific thrust equation will be developed from the unsteady momentum conservation equation. It will be shown that analyses which assume a uniform state 4 for the PGC Atkinson/Humphrey cycle, though convenient in that they typically have closed form algebraic solutions, will generally over-predict ideal specific thrust, and often under-predict specific thrust when component losses (e.g., nozzles) are included. The significance of the under and over-predictions will be discussed.

\section{Fundamental Relationships}

All of the analysis to follow will utilize normalized (i.e., non-dimensional) variables, as this simplifies the equations. Temperature, pressure, and density are normalized by the freestream static values at station 0 . Velocity is normalized by the freestream speed of sound. The brief subsections below will develop some relationships that will be useful in the analysis to follow 


\section{Conservation of Mass and Energy}

Consider a control volume through which periodically flows an inviscid, reacting fluid. For simplicity, the control volume is assumed quasi-one-dimensional. The equation of continuity is

$$
\frac{\partial \rho A}{\partial \tau}+\frac{\partial(\rho u A)}{\partial x}=0
$$

Here, $\tau$ is the time normalized by $L / a_{0}$. The spatial dimension is normalized by $L$. Integration of Equation (2) over the length and period respectively, yields

$$
\int_{0}^{\mathrm{T}} \int_{0}^{1} \rho A d x d \tau=\int_{0}^{T}\left(\rho_{\text {in }} u_{\text {in }} A_{\text {in }}\right) d \tau-\int_{0}^{T}\left(\rho_{\text {out }} u_{\text {out }} A_{\text {out }}\right) d \tau
$$

The subscripts "in" and "out" refer to the entrance and exit planes of the volume, respectively. By the definition of periodicity (i.e., nothing can be stored within the volume over the course of one cycle), the left hand side of Equation (3) is zero. Thus, whatever mass flows in must flow out in one limit cycle.

An analogous process can be followed for the energy equation. The result, in terms of a single species, premixed, reacting flow (again, for simplicity) is

$$
\int_{0}^{T} \rho_{\text {in }} u_{\text {in }} A_{\text {in }}\left(T_{t_{-} \text {in }}+q_{0} z_{\text {in }}\right) d \tau=\int_{0}^{T} \rho_{\text {out }} u_{\text {out }} A_{\text {out }}\left(T_{t_{-} \text {out }}+q_{0} z_{\text {out }}\right) d \tau
$$

Here, $z$ is the reactant mass fraction which is 1 before the reaction starts and zero when it is finished. Like Equation (3), Equation (4) simply verifies that no energy is stored in the volume over one cycle. In the simple control volume cycle that is under consideration, it is stipulated that the reaction must take place within the vessel. Thus $z_{\text {out }}=0$ at all times. It is also stipulated that no partial fueling of the volume occur. Thus, $z_{\text {in }}=1.0$, at all times. Note that nothing has been stipulated about the nature of the reaction (detonative or deflagrative).

Mass averaging, in this case of the total temperature, is defined using the overbar notation as

$$
\bar{T}_{t}=\frac{\int_{0}^{M} T_{t} d m}{M}=\frac{\int_{0}^{T} \rho u A T_{t} d t}{\int_{0}^{T} \rho u A d t}
$$

Combining Equations (3), (4), and (5) and using the station numbering shown in Figure 2 yields the following important relationship

$$
\bar{T}_{t 4}=\bar{T}_{t 3}+q_{0}
$$

For steady flow control volumes such as the Brayton cycle combustor, it is easily shown that Equation (6) is valid with the mass averages replaced by the steady values. For the PGC Atkinson cycle under consideration, it has been assumed that $T_{t 3}$ is steady, hence $T_{t 3}=\bar{T}_{t 3}$. 


\section{Constant Volume Combustion}

In presenting Equations (2) to (6), no assumptions were made about the uniformity or velocity of the fluid within the control volume. For the remainder of this paper, discussion will return to the originally stated simplifying assumptions that the fluid is uniform and at very low (often zero) velocity. Constant volume combustion implies both a fixed volume and mass during the reaction. Thus, the density of the fluid is constant. From the first law of thermodynamics, it is found that the release of chemical energy (combustion) can only increase the internal energy of the fluid. Using the heat addition parameter of Equation (1), the following relationship may therefore be obtained for the instantaneous, peak value of $T_{t 4}$ in the PGC Atkinson cycle.

$$
T_{t 4 \_ \text {peak }}=T_{t 3}+\gamma q_{0}
$$

Two important observations are brought to light with Equations (6) and (7). The first is simply that while $T_{t 4}$ peak is always greater than the peak temperature of the constant pressure Brayton combustor (for the same specific heat addition), the specific enthalpies (essentially the mass averaged total temperatures) of the flows exiting the two combustors are the same.

The second, related observation is that while all of the fluid in the PGC combustor momentarily reaches $T_{t 4}$ _peak, only an infinitesimal amount actually leaves the combustor at this temperature. In the notional PGC cycle, the blowdown phase commences immediately following the constant volume combustion event. An infinitesimal mass of fluid, exits the combustor, accelerates through the nozzle, and

leaves the system. The mass has the energy associated with $T_{t 4 \text { peak. }}$. If an infinitesimal amount of mass and energy leave the combustor, and nothing is being added to the combustor, it follows that the energy (temperature) and mass remaining in the combustor must decrease. Therefore, the next infinitesimal mass of fluid to leave the combustor does so at a lower temperature than $T_{t 4 \_ \text {peak }}$. This incremental decrease of the combustor temperature continues until the blowdown process is complete. The mass average of all these temperatures is $\bar{T}_{t 4}$, from Equations (6). Another interpretation of this process is that each infinitesimal mass of exiting fluid is forced from the combustor by infinitesimal expansion of all the mass that remains. In other words, there is work done by the remaining static fluid on the mass that is leaving (Ref. 17). The important implications of this observation are that: a) $T_{t 4}$ peak does not fully represent the energy available for thrust or useful work extraction, b) $T_{t 4 \text { peak }}$ does not represent a temperature to which any downstream component (e.g., a nozzle) would be continually exposed or able to fully utilize, and c) the difference between $T_{t 4}$ peak and $\bar{T}_{t 4}$ is work done internally to accelerate the combustion products from the combustor.

With reference to Figure 2, these observations illustrate that simply because the PGC Atkinson $T_{t 4}$ peak is greater than the Brayton $T_{t 4}$ does not, by itself, indicate greater work available from the PGC Atkinson cycle. Conversely, when efficiencies are applied to the PGC Atkinson cycle (discussed later), the cycle cannot be debited solely based on $T_{t 4 \text { _peak }}$, since it does not fully represent the actual energy of the flow exiting the combustor. In fact, a more representative expansion 'state' from which to compare the PGC Atkinson cycle to the Brayton cycle is $\bar{T}_{t 4}$ at $\mathrm{s}_{4}$.

\section{Entropy Change}

From the definition of isobaric and isochoric processes, and the ideal specification that the entropy change in the PGC Atkinson cycle from point 3 to point 4 in Figure 2 is the same as from point 9 to point 0 , it may be shown that

$$
T_{9}=\left(\frac{T_{t 4 \_ \text {peak }}}{T_{t 3}}\right)^{\frac{1}{\gamma}}
$$


In the ideal PGC Atkinson cycle, the exit static pressure and entropy are fixed. For a perfect gas, this means that $T_{9}$ is also constant, even though $T_{t 4}$ varies.

\section{Velocity}

The instantaneous velocity may be found from total and static temperatures as follows.

$$
u^{2}=\frac{2}{(\gamma-1)}\left(T_{t}-T\right)
$$

\section{Ideal Efficiency and Kinetic Energy}

The efficiency of any thermodynamic cycle may be defined in terms of rejected and supplied heat. In the nomenclature of the present work, this takes the following form.

$$
\eta_{t h}=1-\frac{\left(T_{9}-1\right)}{q_{0}}
$$

As noted above for the ideal PGC Atkinson cycle, $T_{9}$ is constant even though the cycle is periodic and unsteady. As such, Equation (10) does not require a steady flow assumption and correctly represents thermal efficiency. Equations (7), (8) and (10) can be combined to yield the familiar cycle thermal efficiency which requires only fixed parameters, but which is valid for the unsteady cycle (Ref. 2).

$$
\eta_{t h}=1-\frac{1}{q_{0}}\left[\left(1+\frac{\gamma q_{0}}{T_{t 3}}\right)^{\frac{1}{\gamma}}-1\right]
$$

In the context of the pure thrust device under investigation, efficiency can also be defined as the ratio of net kinetic energy produced to heat added. Since the PGC Atkinson cycle is unsteady however, it must be formally stated in terms of mass averages where they are relevant.

$$
\eta_{t h}=\frac{(\gamma-1)}{2 q_{0}}\left(\overline{u_{9}^{2}}-u_{0}^{2}\right)
$$

The fact that Equations (10) and (12) yield the same result may be verified by substituting Equation (9) as the mass averaged variable in Equation (5), and using Equation (6) with the result. Equation (12) can be rearranged and solved for the mass averaged square of the exit velocity.

$$
\overline{u_{9}^{2}}=\frac{2 q_{0} \eta_{t h}}{(\gamma-1)}+u_{0}^{2}
$$

Evidently, evaluating the mass averaged square of the exit velocity, which involves integrating the non-uniform square of the exit velocity (see Eq. (5)), has a closed form, algebraic solution which depends only on known flow parameters. This was also found to be the case for the evaluating the mass average of the non-uniform $T_{t 4}$ (see Eq. (6)). As will be seen in the next section, this is not true of other mass averaged quantities. 


\section{Specific Thrust}

Specific thrust is typically defined as the thrust per unit of mass flow rate and is often associated with steady flow devices. In the context of an unsteady PGC device, it is defined as the time averaged thrust per unit of time averaged flow rate. However, specific thrust is dimensionally the same, and may also be interpreted as specific impulse. Specific impulse is the change in momentum per unit mass of fluid, or, in the case of PGC, the change in momentum per cyclic mass of fluid processed. For the ideal notional PGC device under consideration the exiting momentum per cyclic mass of fluid is simply the mass averaged velocity at station 9 (see Eq. (5)). The net specific thrust is therefore found by subtracting the (assumed steady) inlet velocity from $\bar{u}_{9}$.

$$
\frac{T_{s p} g_{c}}{a_{0}}=\bar{u}_{9}-u_{0}
$$

The mass averaged exit velocity cannot be evaluated in closed form. However, it can be evaluated using a straightforward numerical integration as follows. Because the flow is isentropic after the instantaneous constant volume combustion process, and due to simplifying assumptions presented earlier, the temperature and pressure in the combustion chamber and nozzle exit (stations 4 and 9) are known functions only of the chamber density, as is the exit velocity. During the blowdown period, spatial integration of Equation (2) shows that

$$
-d \rho_{t 4}=\rho_{9} u_{9} A_{9} d \tau
$$

Blowdown ends when the chamber pressure, $p_{t 4}$ reaches $p_{t 3}$. At this point, refill begins. Using the constant volume combustion relationship $p_{t 4 \_ \text {peak }} / p_{t 3}=T_{t 4 \_ \text {peak }} / T_{t 3}$, the chamber density is found as follows.

$$
\rho_{t 4 \_ \text {refill }}=\rho_{t 3}\left(\frac{p_{t 3}}{p_{t 4 \_ \text {peak }}}\right)^{\frac{1}{\gamma}}=\rho_{t 3}\left(\frac{T_{t 3}}{T_{t 4 \_ \text {peak }}}\right)^{\frac{1}{\gamma}}
$$

During the refill period, the assumption of an exit throat maintaining negligible fill Mach number, insures that no further expansion takes place in the chamber. Thus, the conditions in the chamber and at the nozzle exit remain constant.

Equations (15) and (16) can be used in the general form of Equation (5) to show that the mass average of any function of the chamber density, $f\left(\rho_{t 4}\right)$ may be evaluated as

$$
\bar{f}=\frac{-\int_{\rho_{t 3}}^{\rho_{t 4} \text { refill }} f\left(\rho_{t 4}\right) d \rho_{t 4}+f\left(\rho_{t 4 \_ \text {refill }}\right) \rho_{t 4 \_ \text {refill }}}{\rho_{t 3}}
$$

Thus, from Equations (9) and (17), and standard isentropic relationships, the mass average exit velocity is written as

$$
\bar{u}_{9}=\frac{-\sqrt{\frac{2}{\gamma-1}}\left[\int_{\rho_{t 3}}^{\rho_{t 4} \text { refill }}\left(T_{t 4} \_ \text {peak } \rho_{t 4}^{(\gamma-1)}-T_{9}\right)^{\frac{1}{2}} d \rho_{t 4}-\left(T_{t 4} \_ \text {peak } \rho_{t 4}^{(\gamma-1)} \text { refill }-T_{9}\right)^{\frac{1}{2}} \rho_{t 4} \text { refill }\right]}{\rho_{t 3}}
$$


As mentioned, this integral must be evaluated numerically. As such, Equation (18) will be referred to as the integrated analysis for the remainder of the paper. Figure 4 shows the distribution of pressure and temperature in the chamber for the particular cycle illustrated in Figure 2. Also shown for reference are the exit static and mass average chamber temperatures. These distributions are used to evaluate $u_{9}$, the integrand of Equation (18), which is shown in Figure 4. Also shown are the square of the exit velocity and the numerically obtained, mass averages. It is noted that the numeric 20-point, trapezoidally integrated value of $\overline{u_{9}^{2}}=11.267$. The analytical value from Equation (13) is 11.270, which indicates that the numerical integration is done correctly.

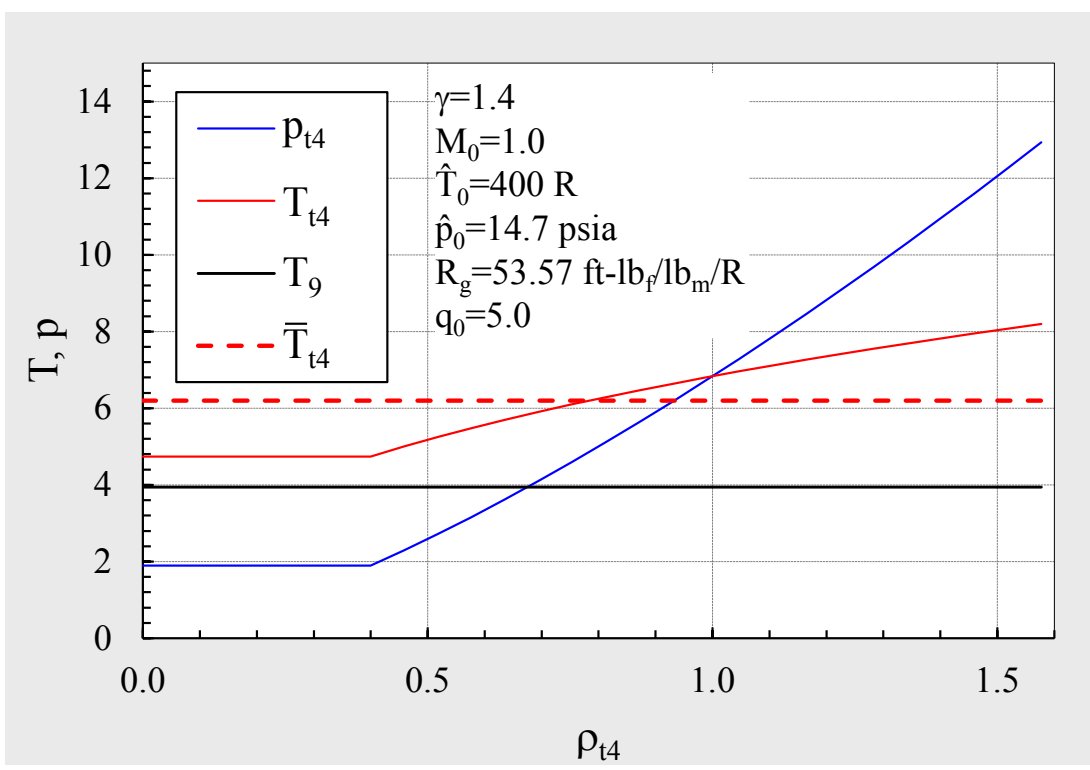

Figure 4.-Distribution of pressure and temperature in the combustion chamber for the idealized Atkinson cycle under the parametric conditions shown.

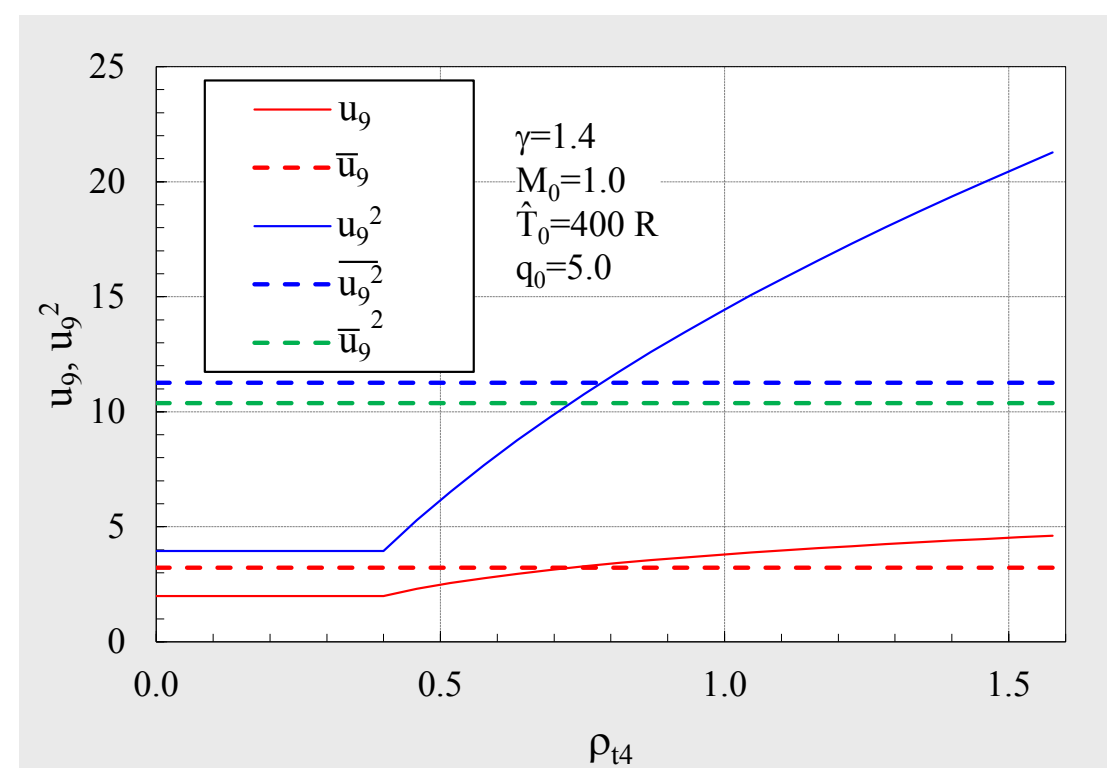

Figure 5.-Distribution of nozzle exit velocity for the idealized Atkinson cycle under the parametric conditions shown. 
Figure 5 illustrates a central tenet of this paper which is that in fundamentally unsteady, thrust producing PGC systems, the momentum (specific thrust) is not algebraically related to the kinetic energy (essentially Eq. (13)). In equation form, this means

$$
\bar{u}_{9} \neq \sqrt{\overline{u_{9}^{2}}}
$$

In steady systems such as the ram Brayton cycle, $u_{9}=\sqrt{u_{9}^{2}}$. As such, ideal thermal efficiency can be obtained algebraically from known cycle parameters, and the steady forms of Equations (13) and (14) still hold. Thus, for steady thrust producing systems, the following may be written.

$$
\frac{T_{s p} g_{c}}{a_{0}}=\sqrt{\frac{2 q_{0} \eta_{t h}}{(\gamma-1)}+u_{0}^{2}}-u_{0}
$$

Failure to recognize Equation (19), which is quite subtle, has led researchers to apply the steady Equation (20) to unsteady PGC Atkinson cycle analyses (Ref. 2). These will be referred to as algebraic analyses for the remainder of the paper. Their results, even if the appropriate thermal efficiency is used (Eq. (11)), are incorrect.

A more general statement than Equation (19) can be made on the relationship between $\bar{u}_{9}$ and $\sqrt{\overline{u_{9}^{2}}}$. Consider an arbitrary periodic exit velocity profile arising from detonative or deflagrative PGC. At any point in the cycle, this velocity may be written as $u_{9}=\bar{u}_{9}+u_{9}^{\prime}$, where $u_{9}^{\prime}$ represent a deviation from the mass averaged value obtained via Equation (17). Squaring this quantity yields $u_{9}^{2}=\bar{u}_{9}^{2}+u_{9}^{\prime 2}+2 \bar{u}_{9} u_{9}^{\prime}$. Taking the mass average of $u_{9}^{2}$ and noting that $\overline{u_{9}^{\prime}}=0$ by definition yields

$$
\overline{u_{9}^{2}}=\bar{u}_{9}^{2}+\overline{u_{9}^{\prime 2}}
$$

Thus, $\bar{u}_{9}=\sqrt{\overline{u_{9}^{2}}}$ only if $\overline{u_{9}^{\prime 2}}=0$, that is, only if the flow is uniform or steady. Furthermore, since the mass averaged square of the deviation $\overline{u_{9}^{\prime 2}}$ is greater than zero for all periodic unsteady flows, it follows that

$$
\bar{u}_{9} \leq \sqrt{\overline{u_{9}^{2}}}
$$

As such, the correct ideal net specific thrust from Equations (18) (combined with Eq. (14)) is always less than that computed from Equation (20).

\section{Results and Discussion}

Equation (22), describing the relationship between mass averaged momentum and energy fluxes represents the unavoidable impact of unsteadiness on PGC performance as measured by specific thrust. In fact, Reference 18 describes the ratio $\bar{u}_{9}^{2} / \overline{u_{9}^{2}}$ as the 'efficiency of non-uniformity'. It is interesting to note as a relevant aside that if the PGC Atkinson cycle considered here were implemented as a classical control mass Atkinson cycle (e.g., with pistons), the fact that it is unsteady would have no impact on performance. In this case, Equation (11) would still hold and the performance metric, net specific piston work, would be directly calculable from it. In other words, the control volume nature of the PGC 
Atkinson cycle, and the fact that momentum is the relevant performance metric (not piston work) give rise to a sort of 'loss' described by Equation (22).

Figure 6 compares the specific thrust of the algebraic (Eq. (20)) and integrated (Eqs. (18) and (14)) analyses over a range of flight Mach numbers, at a constant freestream temperature. For reference, the specific thrust for the ideal Brayton cycle is also shown. As expected, the algebraic analysis over-predicts performance compared to the integrated state-based model, and the disparity is greatest where the nonuniformity of $\overline{u_{9}^{\prime 2}} / \bar{u}_{9}^{2}$ is greatest over the course of the cycle.

\section{Performance With Losses}

Thus far the analysis has focused on ideal performance analysis. In this section the impact of component efficiency and fundamental unsteadiness will be examined. Specifically, the nozzle efficiency will be varied, since it is in the expansion phase of the PGC Atkinson cycle that the effects of unsteadiness are manifested. The nozzle efficiency is defined as follows

$$
\eta_{e}=\frac{T_{t 4}-T_{9}}{T_{t 4}-T_{9 i}}=\frac{1-\frac{T_{9}}{T_{t 4}}}{1-P_{t 4}^{\left(\frac{1-\gamma}{\gamma}\right)}}
$$

Equation (23) complicates the PGC Atkinson T-s diagram of Figure 2 since each infinitesimal unit of mass not only has a different $P_{t 4}$, and $T_{t 4}$, but also has a different $\mathrm{T}_{9}$. In other words, each unit of mass follows a different path to the specified exit static pressure line. Mathematically however, it is a simple matter to solve Equation (23) for $T_{9}$, isentropically relate $P_{t 4}$, and $T_{t 4}$ to $P_{t 4}$, and $\rho_{t 4}$, insert it into the integral of Equation (18) and subsequently obtain specific thrust. It is also noted (though results will not be shown), that cycle thermal efficiency is no longer algebraically obtained. It too requires numerical integration.

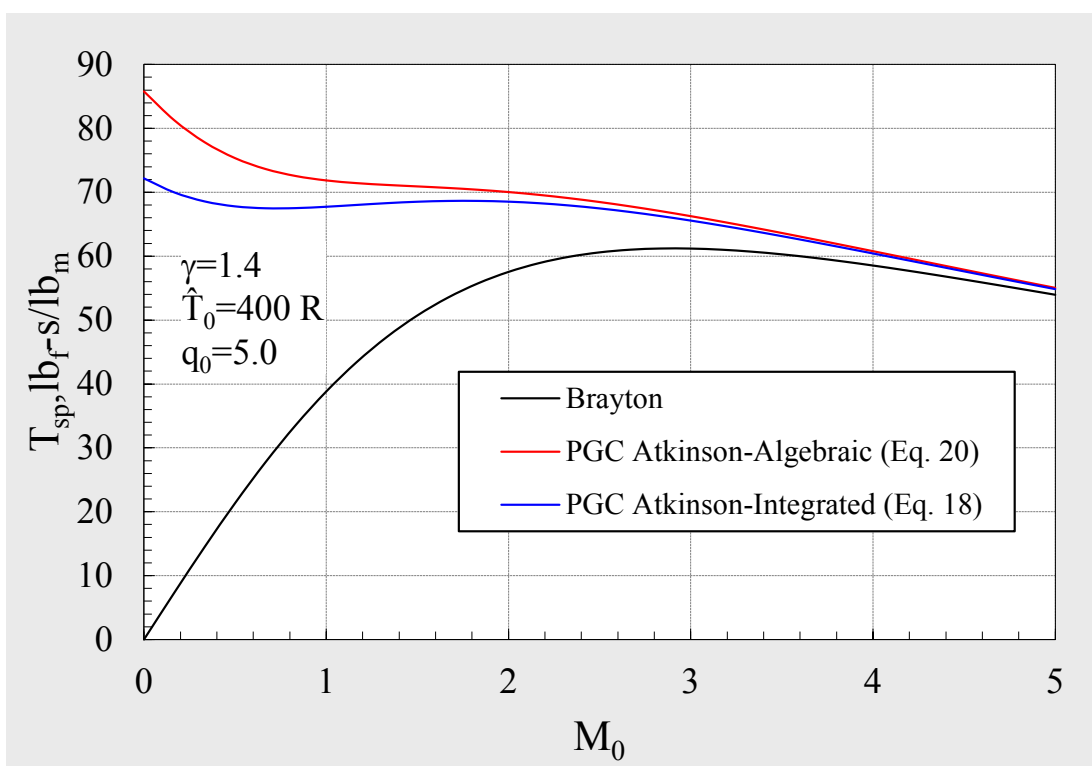

Figure 6.-Ideal specific thrust as a function of Mach number for the PGC Atkinson cycle using the algebraic and integrated analyses. 
Algebraic analyses, which do not recognize Equation (19), and which rely on steady relationships such as Equation (20) often utilize a single value for $T_{9}$ and it is typically found by using $T_{t 4 \text { _peak }}$ and $P_{t 4 \text { _eak }}$ in Equation (23) (i.e., using condition that generate maximum entropy) (Ref. 2). This is equivalent to treating the entire PGC Atkinson cycle as a steady process. ${ }^{1}$ This results in a larger performance penalty being incurred by the algebraic model than by the integrated state model for the same specified expansion efficiency.

Figure 7 shows this effect using the same format as Figure 6. The expansion efficiency chosen is $\eta_{\mathrm{e}}=0.90$. It is seen that the algebraic analysis incorrectly penalizes the PGC Atkinson cycle so severely that its performance drops below that of the integrated analysis, and even below the performance of the Brayton cycle.

It is noted in passing that more realistic performance results could be obtained from the algebraic analysis by calculating $T_{9}$ by using $\bar{T}_{t 4}$ from Equation (6) and $p_{t 4}=p_{t 4} \_$peak $\left(\frac{\bar{T}_{t 4}}{T_{\text {t4_peak }}}\right)^{\frac{\gamma}{\gamma-1}}$ in Equation (23). Doing so would yield algebraic performance results which were everywhere better than the integrated results, as would be expected from neglecting the effects of non-uniformity. Such results are not shown however, as it is the proposition of this paper that algebraic analyses are not appropriate for PGC Atkinson cycle performance analysis.

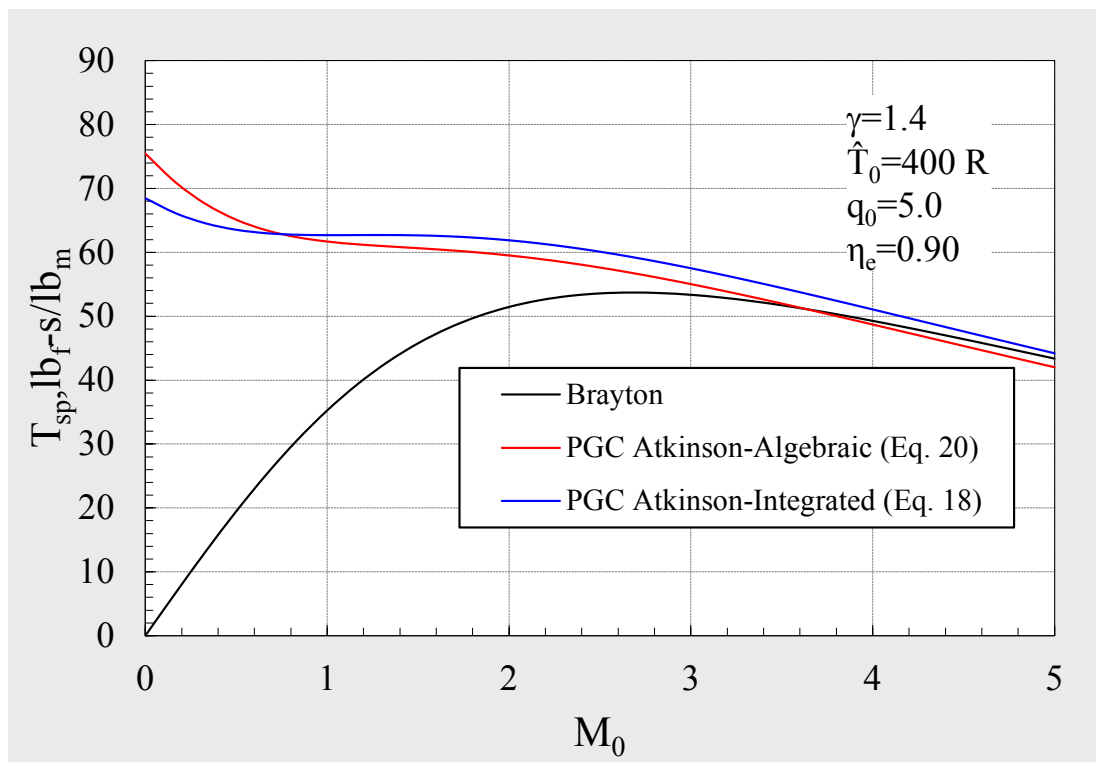

Figure 7.-Specific thrust with expansion loss as a function of Mach number for the PGC Atkinson cycle using the algebraic and integrated analyses.

\footnotetext{
${ }^{1}$ It is noted that if a classical (control mass, piston-based) Atkinson cycle were under consideration, and Equation (23) was a piston work efficiency rather than a nozzle expansion efficiency, the use of a single $T_{9}$, along with $P_{t 4}$ peak and $T_{t 4 \text { peak }}$ would be perfectly appropriate since all the mass in this case would follow the same path.
} 


\section{Energy Conservation in Equation (17)}

This paper will close with a brief discussion that does not directly follow the previous sections. It is included because the authors believe that Equation (17), with its state-based integration (as opposed to time-based), is a somewhat unconventional manner by which to describe mass averaging and therefore requires some additional proof as to its validity. To do so, Equation (6), which is a mass average demonstrating the cyclic conservation of energy in a control volume is re-derived from Equation (17) as follows.

$$
\bar{T}_{t 4}=\frac{-\int_{\rho_{t 3}}^{\rho_{t 4}-\text { refill }} T_{t 4} d \rho_{t 4}+T_{t 4}{ }_{-} \text {refill } \rho_{t 4} \rho_{-} \text {refill }}{\rho_{t 3}}
$$

Using isentropic relations, $T_{t 4}$ can be made a function of $\rho_{t 4}$ and other known quantities.

$$
\bar{T}_{t 4}=\frac{-\frac{T_{t 4 \_ \text {peak }}}{\rho_{t 3}^{(\gamma-1)}}\left[\int_{\rho_{t 3}}^{\rho_{t 4} \text { _refill }} \rho_{t 4}^{(\gamma-1)} d \rho_{t 4}-\rho_{t 4 \_ \text {refill }}^{\gamma}\right]}{\rho_{t 3}}=\frac{1}{\gamma}\left[(\gamma-1) T_{t 3}+T_{t 4 \_ \text {peak }}\right]=T_{t 3}+q_{0}
$$

Here, Equation (7) has also been employed to produce the final result, which is Equation (6).

\section{Conclusions}

This paper has described and quantified the influence of inherent unsteadiness on fixed volume pressure gain combustion (PGC) system performance and the analysis thereof. Using a simple notional PGC device executing an Atkinson cycle, it has been shown that unsteadiness impacts the fundamental cycle diagram interpretation. Specifically, it was shown that a direct comparison of unsteady cycle and steady cycle states cannot be used to compare performance. A consistent means of addressing mass, momentum and energy conservation has been presented which provides the ability to properly compare unsteady and steady cycle performance. Finally, it has been shown that only through the proper accounting for unsteadiness can component losses be properly applied to cycle performance. 



\section{Appendix-Symbols List}

$\begin{array}{ll}a_{0} & \text { freestream speed of sound } \\ c_{p} & \text { specific heat at constant pressure } \\ c_{v} & \text { specific heat at constant volume } \\ f / a & \text { fuel to air ratio (by mass) } \\ g_{c} & \text { Newton constant } \\ m & \text { mass } \\ p & \text { nondimensional pressure } \\ \hat{p} & \text { pressure } \\ q_{0} & \text { nondimensional heat addition parameter } \\ s & \text { entropy } \\ u & \text { nondimensional velocity } \\ x & \text { nondimensional axial distance } \\ z & \text { reactant concentration } \\ A & \text { area } \\ L & \text { length } \\ T & \text { nondimensional temperature } \\ \hat{T} & \text { temperature } \\ T_{s p} & \text { specific thrust } \\ T & \text { nondimensional period } \\ \gamma & \text { ratio of specific heats } \\ \eta & \text { efficiency } \\ \rho & \text { nondimensional density } \\ \tau & \text { nondimensional time } \\ \Delta h_{v} & \text { fuel heating value } \\ & \end{array}$

\section{Subscripts}

$\begin{array}{ll}0 & \text { freestream } \\ 3 & \text { ram diffuser outlet } \\ 4 & \text { combustion chamber } \\ 9 & \text { nozzle exit plane } \\ e & \text { expansion } \\ i & \text { isentropic } \\ \text { in } & \text { entering quantity } \\ \text { out } & \text { exiting quantity } \\ \text { peak } & \text { maximum in the cycle } \\ t & \text { total } \\ t h & \text { thermal }\end{array}$

\section{Superscripts}

- $\quad$ overbar signifying a mass average

' deviation from the mean 


\section{References}

1. Schauer, F.R., et al., "Detonation Initiation Studies and Performance Results for Pulsed Detonation Engine Applications," AIAA 2001-1129, Jan. 2001.

2. Heiser, W. H., Pratt, D. T., "Thermodynamic Cycle Analysis of Pulse Detonation Engines," Journal of Propulsion and Power, Vol. 18, No. 1, pp. 68-76, 2002.

3. Kentfield, J.A.C., "Thermodynamic of Airbreathing Pulse-Detonation Engines," Journal of Propulsion and Power, Vol. 18, No. 6, pp. 1170-1175, 2002.

4. Nalim, M.R., "Thermodynamic Limits of Work and Pressure-Gain in Combustion and Evaporation Processes," Journal of Propulsion and Power, Vol. 18, No. 6, pp. 1176-1182, 2002.

5. Brophy, C., Sinabaldi, J., "Performance Characterization of a Valveless Pulse Detonation Engine," AIAA-2003-1344, Jan. 2003.

6. Kaemming, T., Dyer, R., "The Thermodynamic and Fluid Dynamic Functions of a Pulsed Detonation Engine Nozzle,” AIAA-2004-3916, Jul. 2004.

7. Paxson, D.E., "Performance Evaluation Method for Ideal Airbreathing Pulse Detonation Engines," Journal of Propulsion and Power, Vol. 20, No. 5, pp. 945-950, 2004.

8. Perkins, H.D., et al., "An Assessment of Pulse Detonation Engine Performance Estimation Methods Based On Experimental Results," AIAA-2005-3831, Jul. 2005.

9. Rasheed, Furman, and Dean, "Experimental Investigations of an Axial Turbine Driven by a Multitube Pulsed Detonation Combustor System", AIAA 2005-4209.

10. Kojima, et al., "Design Study of Turbine for Pulse Detonation Combustor," AIAA 2007-5081, Jul. 2007.

11. Van Zante, Envia, and Turner, "The Attenuation of a Detonation Wave by an Aircraft Engine Axial Turbine Stage," ISABE-2007-1260, Sep. 2007.

12. Caldwell, et al., "Experimental Analysis of a Hybrid Pulse Detonation Combustor / Gas Turbine Engine," AIAA-2008-121.

13. Suresh, A., Hofer, D.C., Tangirala, V.E. "Turbine Efficiency for Unsteady, Periodic Flows," AIAA 2009-0504, Jan. 2009.

14. Paxson, D.E., "A Simplified Model for Detonation Based Pressure-Gain Combustors," AIAA 20106717, Jul. 2010.

15. Rouser, K.P., et al., "Unsteady Performance of a Turbine Driven by a Pulse Detonation Engine," AIAA-2010-1116, Jan. 2010.

16. Paxson, D. E., Brophy, C., Bruening, G., "Performance Evaluation of a Pulse Detonation Combustion Based Propulsion System Using Multiple Methods," JANNAF Journal of Propulsion and Energetics, Vol. 3, No. 1, May, 2010, pp. 44-55.

17. Sun, G., Akbari, P., Gower, B., Muller, N., "Thermodynamics of the Wave Disk Engine," AIAA 2012-3704, Aug. 2012.

18. Foa, J. V., Elements of Flight Propulsion, Wiley, New York, 1959, pp. 274-283. 



\begin{tabular}{|c|c|c|}
\hline \multicolumn{2}{|c|}{ REPORT DOCUMENTATION PAGE } & $\begin{array}{l}\text { Form Approved } \\
\text { OMB No. 0704-0188 }\end{array}$ \\
\hline \multicolumn{3}{|c|}{ 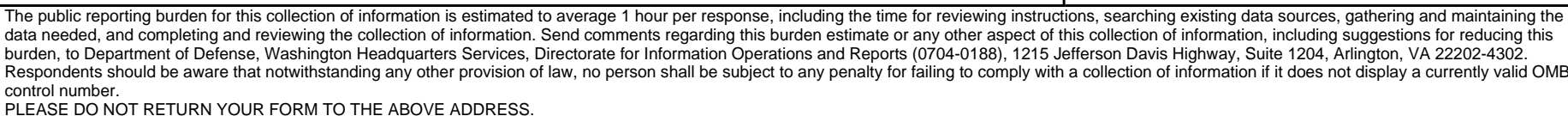 } \\
\hline $\begin{array}{l}\text { 1. REPORT DATE (DD-MM-YYYY) } \\
01-01-2013\end{array}$ & $\begin{array}{l}\text { 2. REPORT TYPE } \\
\text { Technical Memorandum }\end{array}$ & 3. DATES COVERED (From - To) \\
\hline \multirow{3}{*}{\multicolumn{2}{|c|}{$\begin{array}{l}\text { 4. TITLE AND SUBTITLE } \\
\text { The Influence of Unsteadiness on the Analysis of Pressure Gain Combustion Devices }\end{array}$}} & 5a. CONTRACT NUMBER \\
\hline & & 5b. GRANT NUMBER \\
\hline & & 5c. PROGRAM ELEMENT NUMBER \\
\hline \multirow{3}{*}{\multicolumn{2}{|c|}{$\begin{array}{l}\text { 6. AUTHOR(S) } \\
\text { Paxson, Daniel, E.; Kaemming, Tom }\end{array}$}} & 5d. PROJECT NUMBER \\
\hline & & 5e. TASK NUMBER \\
\hline & & $\begin{array}{l}\text { 5f. WORK UNIT NUMBER } \\
\text { WBS 031102.02.03.0832.11 }\end{array}$ \\
\hline \multicolumn{2}{|c|}{$\begin{array}{l}\text { 7. PERFORMING ORGANIZATION NAME(S) AND ADDRESS(ES) } \\
\text { National Aeronautics and Space Administration } \\
\text { John H. Glenn Research Center at Lewis Field } \\
\text { Cleveland, Ohio 44135-3191 }\end{array}$} & $\begin{array}{l}\text { 8. PERFORMING ORGANIZATION } \\
\text { REPORT NUMBER } \\
\text { E-18582 }\end{array}$ \\
\hline \multirow{2}{*}{\multicolumn{2}{|c|}{$\begin{array}{l}\text { 9. SPONSORING/MONITORING AGENCY NAME(S) AND ADDRESS(ES) } \\
\text { National Aeronautics and Space Administration } \\
\text { Washington, DC 20546-0001 }\end{array}$}} & $\begin{array}{l}\text { 10. SPONSORING/MONITOR'S } \\
\text { ACRONYM(S) } \\
\text { NASA }\end{array}$ \\
\hline & & $\begin{array}{l}\text { 11. SPONSORING/MONITORING } \\
\text { REPORT NUMBER } \\
\text { NASA/TM-2013-217831 }\end{array}$ \\
\hline \multicolumn{3}{|c|}{$\begin{array}{l}\text { 12. DISTRIBUTION/AVAILABILITY STATEMENT } \\
\text { Unclassified-Unlimited } \\
\text { Subject Category: } 07 \\
\text { Available electronically at http://www.sti.nasa.gov } \\
\text { This publication is available from the NASA Center for AeroSpace Information, 443-757-5802 }\end{array}$} \\
\hline
\end{tabular}

\section{SUPPLEMENTARY NOTES}

\section{ABSTRACT}

Pressure gain combustion (PGC) has been the object of scientific study for over a century due to its promise of improved thermodynamic efficiency. In many recent application concepts PGC is utilized as a component in an otherwise continuous, normally steady flow system, such as a gas turbine or ram jet engine. However, PGC is inherently unsteady. Failure to account for the effects of this periodic unsteadiness can lead to misunderstanding and errors in performance calculations. This paper seeks to provide some clarity by presenting a consistent method of thermodynamic cycle analysis for a device utilizing PGC technology. The incorporation of the unsteady PGC process into the conservation equations for a continuous flow device is presented. Most importantly, the appropriate method for computing the conservation of momentum is presented. It will be shown that proper, consistent analysis of cyclic conservation principles produces representative performance predictions.

\section{SUBJECT TERMS}

Propulsion; Combustion

\begin{tabular}{|c|c|c|c|c|c|}
\hline \multicolumn{3}{|c|}{ 16. SECURITY CLASSIFICATION OF: } & \multirow{2}{*}{$\begin{array}{l}\text { 17. LIMITATION OF } \\
\text { ABSTRACT } \\
\text { UU }\end{array}$} & \multirow{2}{*}{$\begin{array}{l}\text { 18. NUMBER } \\
\text { OF } \\
\text { PAGES } \\
24\end{array}$} & \multirow{2}{*}{$\begin{array}{l}\text { 19a. NAME OF RESPONSIBLE PERSON } \\
\text { STI Help Desk (email:help@sti.nasa.gov) } \\
\text { 19b. TELEPHONE NUMBER (include area code) } \\
\text { 443-757-5802 }\end{array}$} \\
\hline $\begin{array}{l}\text { a. REPORT } \\
U\end{array}$ & $\begin{array}{l}\text { b. ABSTRACT } \\
U\end{array}$ & $\begin{array}{l}\text { c. THIS } \\
\text { PAGE } \\
\text { U }\end{array}$ & & & \\
\hline
\end{tabular}



